\title{
O TURISMO COMO ELEMENTO DINAMIZADOR DO CRESCIMENTO POPULACIONAL DAS LOCALIDADES DE AREMBEPE E IMBASSAÍ, LITORAL NORTE DA BAHIA
}

\author{
Matheus Gomes da Silva; Telma Maria Sousa dos Santos \\ 1. Bolsista PIBIC/FAPESB, Graduando em Bacharelado em Geografia, Universidade Estadual de Feira de Santana, e-mail: \\ matheus19gomes@hotmail.com \\ 2. Telma Maria Sousa dos Santos, Departamento de Ciências Humanas e Filosofia, Universidade Estadual de Feira de \\ Santana, e-mail: telmaarq@yahoo.com.br
}

PALAVRAS-CHAVE: Turismo - expansão urbana - crescimento populacional.

\section{INTRODUÇÃO}

A inserção e consolidação do turismo num determinado espaço provoca consideráveis alterações socioespaciais, onde novas ações e objetos são inseridos, e os já existentes são apropriados para dar suporte à atividade turística, promovendo, assim, a reorganização do espaço. Como resultante dessas alterações, têm-se a dinamização da economia local que acaba atraindo para aqueles espaços turísticos, novos contingentes populacionais. Durante a realização do trabalho referente ao turismo e a expansão urbana nas localidades de Arembepe (município de Camaçari) e Imbassaí (município de Mata de São João) desenvolvido entre os anos 2014-2015 percebeu-se que as localidades investigadas passam por um processo de atração de novos contingentes populacionais. Isso posto, esta pesquisa busca analisar como esse movimento populacional em direção a Arembepe e Imbassaí se relaciona com a atividade turística. Destarte, tem-se como objetivo geral analisar o turismo como elemento dinamizador do crescimento populacional das localidades de Arembepe e Imbassaí.

\section{MATERIAL E MÉTODOS OU METODOLOGIA (ou equivalente)}

Como procedimentos metodológicos, fez-se revisão bibliográfica abordando as seguintes temáticas: Turismo e produção do espaço geográfico, movimentos populacionais e algumas considerações sobre turismo e desenvolvimento. Após a construção do referencial teórico, iniciou-se a parte de coleta de dados secundários. Na primeira viagem de campo, realizada no mês de junho do corrente ano, os dados dos censos de 1991, 2000 e 2010 foram coletados no Instituto Brasileiro de Geografia e Estatística (IBGE), em Salvador. A segunda pesquisa de campo foi realizada, desta vez para aplicação dos questionários com as populações locais de Arembepe e Imbassaí. A intenção era aplicar nas áreas onde já se tinha conhecimento da concentração da população migrante, em cinco loteamentos em cada localidade, no entanto, por conta da dificuldade de mobilidade a área de aplicação dos questionários teve de ser reduzida tanto em Arembepe, quanto em Imbassaí. Também não foi possível obter informações dos poderes públicos municipais de Camaçari, ao qual pertence Arembepe, e de Mata de São João, ao qual pertence Imbassaí. Após a aplicação dos questionários, os dados foram sistematizados, elaborou-se gráficos e tabelas e, posteriormente, a análise e discussão dos resultados obtidos à luz do referencial teórico.

\section{RESULTADOS E/OU DISCUSSÃO (ou Análise e discussão dos resultados)}

Durante pesquisa anterior, entre os anos de 2014 e 2015, verificou-se que a população migrante em Arembepe e Imbassaí está se concentrando nas novas áreas de expansão urbana, a oeste da BA 099. Essa orientação na ocupação espacial tem como causa o fato de terrenos e casas nos núcleos principais das localidades terem preços inacessíveis para essa população, pois em pesquisa anterior a população informou que houve aumento nos preços de casas e 
terrenos à medida que o turismo se consolidava. Assim, as populações de menor poder aquisitivo que para ali se deslocam ocupam as áreas mais afastadas do núcleo principal, onde os questionários foram aplicados.

Em Arembepe, 50\% dos moradores entrevistados residem ali entre um e dez anos. Em Imbassaí, temos que 52\% dos entrevistados residem ali entre 6 e 15 anos. Esses dados obtidos revelam que a imigração de pessoas em Arembepe e Imbassaí continua sendo evidente, um fenômeno populacional que deve ser considerado nessas áreas aonde o turismo vem se desenvolvendo e se consolidando. Quanto à faixa etária, temos um cenário em que a maioria tem entre 41 e 45 anos de idade, o que denota que a maioria dos migrantes se concentra nessa área de expansão da ocupação urbana de Arembepe é de população adulta. Quase metade dos entrevistados em Imbassaí, 42\%, se concentra na faixa etária de 36 à 45 anos. Portanto, o cenário tanto em Arembepe quanto em Imbassaí é de uma maioria de migrantes que se encaixa na faixa de População em Idade Ativa (PIA), classificação etária que compreende o conjunto de todas as pessoas teoricamente aptas a exercer uma atividade econômica, portanto, em condições de se inserir no mercado de trabalho.

Concernente à escolaridade, em Arembepe uma ampla maioria da população (55\%) tem apenas o ensino fundamental completo (até a antiga $8^{a}$ série ou atualmente, $9^{\circ}$ ano). Apenas $11 \%$ afirmaram ter o nível superior. Em Imbassaí, uma situação um pouco melhor, a maioria dos entrevistados inferiu ter o ensino médio, $44 \%$, enquanto que aqueles que têm apenas o ensino fundamental concernem, também, $44 \%$ dos moradores.

Averiguou-se, também, o rendimento mensal da população migrante. Em Arembepe, a maioria, $47 \%$, afirmou ter rendimento mensal de menos de um salário mínimo, ou seja, $\mathrm{R} \$$ 440,00 Em Imbassaí 40\% deles afirmaram ter um rendimento mensal de mais de um salário mínimo, ou seja, acima dos $\mathrm{R} \$ 880,00$. Por outro lado, 38\% dos imigrantes em Imbassaí afirmaram ter um rendimento entre menos de um salário ou afirmaram estar sem rendimento no momento ( $12 \%$ e $16 \%$, respectivamente). Deste modo, cruzando os dados de escolaridade e rendimento, temos um cenário típico de estágio de subdesenvolvimento, onde quanto menor for o nível de escolaridade, menores são as possibilidades de inserção no mercado de trabalho ou de se ocupar postos de trabalho de alto rendimento, por conta do baixo nível de instrução.

Quando se analisa o local de origem dos entrevistados, percebe-se que a maioria vem de cidades do interior, do semiárido baiano, área pouco desenvolvida economicamente. Deste modo, os desequilíbrios econômicos regionais se configuram como uma das principais causas que impulsionam os movimentos populacionais.

Como afirmado, a inserção do turismo promoveu significativas alterações no espaço dessas localidades, dinamizando-o economicamente. Consequentemente tem sido um fator de atração de populações que se deslocam em busca de melhores condições de vida a partir do turismo, uma vez que para populações pobres, esses investimentos mostram-se como oportunidades de trabalho e, portanto, de melhorias na qualidade de vida. Este é o fenômeno que, de acordo com os resultados obtidos, tem acontecido em Arembepe e Imbassaí como denota os gráficos 1.1 e 1.2.

Em Arembepe, $32 \%$ dos entrevistados apontaram como principal motivo de imigração as oportunidades de emprego que se tem na localidade e arredores. Em Imbassaí, esse número foi um pouco maior, $40 \%$. Quando se aglutina este motivo com outros fatores citados, tem-se a seguinte situação: Arembepe $42 \%$ (32\% que citaram apenas emprego e outros $10 \%$ que citaram qualidade de vida e emprego). Em Imbassaí esse número alcança 56\% (40\% que citaram apenas emprego e $16 \%$ que citaram como fatores de atração emprego e qualidade de vida), portanto, a maior parte dos entrevistados.

Outro fator que importa destacar em Arembepe, pois foi o segundo mais citado: "proximidade de parentes". Muitos dos que apontaram essa questão (18\%) afirmam que ali 
vieram morar por conta do deslocamento do chefe de família, assim, os demais familiares tiveram de migrar.

Gráfico 1.1: Motivo de migrar para Arembepe

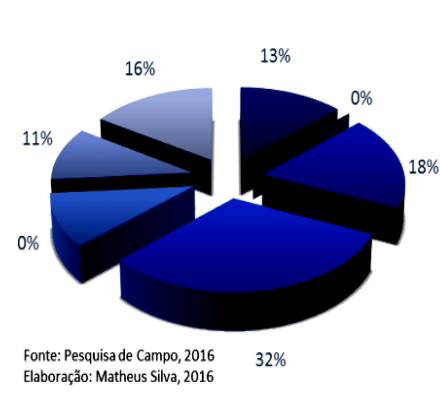

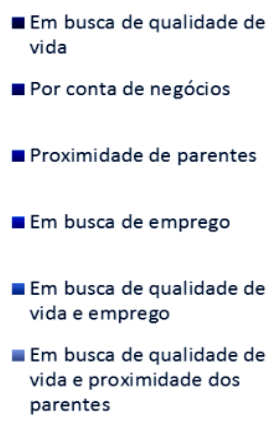

Gráfico 1.2: Motivo de migrar para Imbassaí

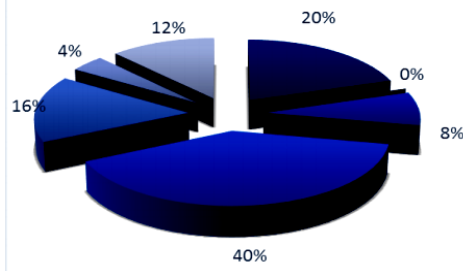

- Em busca de qualidade de vida

- Por conta de negócios

- Proximidade de parentes

- Em busca de emprego

- Em busca de qualidade de vida e emprego

Em busca de qualidade de vida proximidade dos parentes
Outros

Destarte, a questão familiar também está envolvida no movimento migratório. Por outro lado, a fim de não recair num determinismo econômico nessa questão, os movimentos populacionais também podem ser provocada pela busca da tão sonhada qualidade de vida, que não está relacionada apenas a questões econômicas, mas também a questões sociais, culturais e ambientais, o que confere complexidade ao ato de migrar.

Verificou-se também o tempo em que os entrevistados estão morando em Arembepe e Imbassaí. Em Arembepe, 50\% dos moradores entrevistados residem ali entre um e dez anos. Mas também há uma considerável parte dos que moram em Arembepe há mais de 30 anos, foram $17 \%$ dos entrevistados. Estes são, na maioria, pescadores; atividade econômica dos antigos moradores da localidade. Já em Imbassaí, 52\% dos entrevistados residem ali entre 6 e 15 anos, cenário muito próximo daquele encontrado em Arembepe. Esses dados obtidos revelam que a imigração de pessoas em Arembepe e Imbassaí continua sendo evidente, um fenômeno populacional que deve ser considerado nessas áreas onde o turismo vem se desenvolvendo e se consolidando.

Quanto ao acesso à moradia adequada, esta não é uma realidade para muitos dos migrantes. Vale ressaltar que a questão habitacional está relacionada ao mercado de trabalho, pois, como denotado no gráfico 1.1 e 1.2, essas populações que imigraram para Arembepe e Imbassaí, querem morar perto dessas oportunidades de trabalho nesses espaços turísticos. Essas moradias, em alguns casos, são inadequadas (Imagem 1.1). Em Imbassaí pareceu mais notório a ação do poder público municipal nas novas áreas de expansão urbana que estão concentrando a população migrante. Algumas ações verificadas e pontuadas na pesquisa anterior, entre 2014 e 2015, 29 foram: regularização fundiária, urbanização por meio do programa "Minha Casa, Minha Vida" (Imagem 1.2). Portanto, o programa tem sido uma alternativa de ocupação ordenada para essas populações, na ótica do poder público municipal, mas não é regra geral. Há áreas com pouca ou nenhuma infraestrutura urbana para dar boas condições de vida à população migrante (Imagem 1.3)
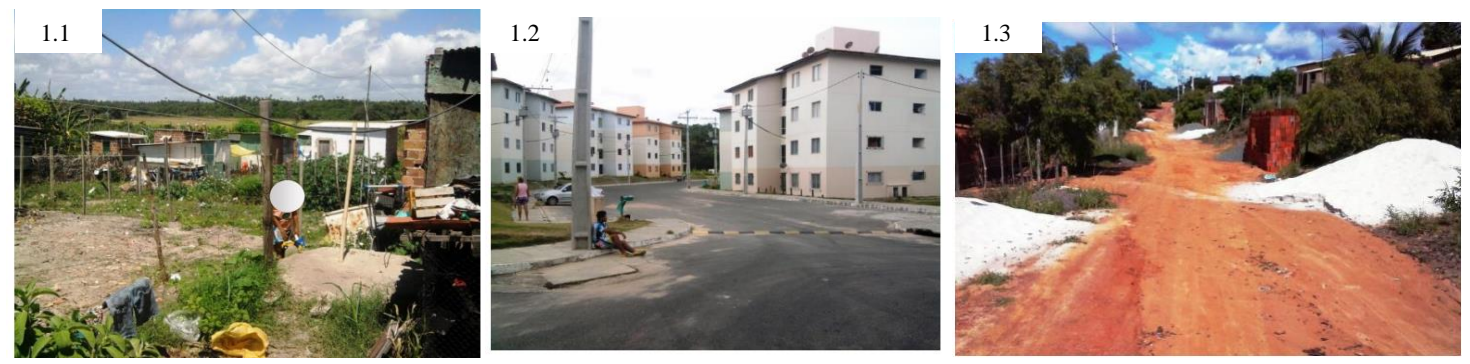
Imagem: 1.1: Área de concentração da população migrante em Arembepe. 1.2: Conjuntos habitacionais de MCMV em Imbassaí. 1.3: Área de concentração de população migrante em Imbassaí.

\section{CONSIDERAÇÕES FINAIS (ou Conclusão)}

Considera-se que os objetivos a que nos propusemos com a realização deste trabalho foram atingidos. Não restam dúvidas de que a inserção da atividade turística em Arembepe e Imbassaí, no Litoral Norte da Bahia, provocou alterações na dinâmica populacional dessas localidades, haja vista ser essa atividade econômica um importante agente modificador socioespacial. A partir dos dados obtidos dos censos, verificou-se que as localidades tiveram crescimento populacional entre 1991 e 2010. Parte desse crescimento deve-se à chegada de migrantes em busca de oportunidades de emprego e qualidade de vida. Percebe-se que as ações de poder público e iniciativas privadas têm contribuído para essa dinâmica populacional. As políticas de dinamização do turismo e de revitalização urbana das localidades, bem como o aquecimento do setor da construção civil se configuram como fatores atrativos de populações em busca de emprego.

As localidades investigadas estão a atrair imigrantes, se expandido espacialmente. Em Arembepe, de modo mais específico, o poder público não tem procurado orientar essa ocupação espacial, ao que se pôde verificar empiricamente na paisagem. É necessário pontuar que o crescimento populacional desordenado pode ocasionar problemas de ordem socioeconômica, bem como questões relacionadas ao ambiente físico, dada à ocupação de áreas ambientalmente frágeis, como já foi constatado em pesquisas anteriores. Em Imbassaí, o poder público tem procurado ordenar a ocupação espacial de algumas áreas seletas. Ademais, verificou-se que o município tem desenvolvido projetos de profissionalização de mão de obra para trabalhar nos serviços voltados ao turismo.

Evidencia-se, por fim, a necessidade de fazer com que a produção de riqueza gerada pelo turismo seja compartilhada, que haja distribuição social, considerando os princípios de equidade, para que as necessidades das populações sejam atendidas. O que se preconiza é uma sociedade justa, com o turismo contribuindo com a elevação da qualidade dessas populações mais pobres, excluídas, que migram em busca de melhores condições de vida.

\section{REFERÊNCIAS}

CRUZ, Rita de Cássia Ariza da. Introdução á Geografia do Turismo. $2^{a}$ ed. São Paulo-SP: Roca, 2003.

CRUZ, Rita de Cássia Ariza da. Geografia do Turismo. De lugares a pseudo-lugares. 2007.

DAMIANI, Amélia Luisa. População e geografia. 2. ed. São Paulo, SP: Contexto, 1996.

SANTOS, Telma Maria Sousa dos. Turismo e urbanização em espaços litorâneos: um olhar sobre a Praia do Forte-Bahia. Feira de Santana-BA: UEFS Editora, 2013. 